https://helda.helsinki.fi

\title{
Scientific realism and ontology
}

\section{Mäki, Uskali}

Palgrave Macmillan

2008

Mäki , U 2008 , Scientific realism and ontology . in S N Durlauf \& L E Blume (eds), The New Palgrave Dictionary of Economics : volume 7 : real balances - stochastic volatility models . 2nd edn, vol. 7 , Palgrave Macmillan, Basingstroke, pp. 334 - 341.

http://hdl.handle.net/10138/232216

acceptedVersion

Downloaded from Helda, University of Helsinki institutional repository.

This is an electronic reprint of the original article.

This reprint may differ from the original in pagination and typographic detail.

Please cite the original version. 


\title{
Scientific realism and ontology
}

\author{
Uskali Mäki
}

Academy of Finland

For The New Palgrave Dictionary of Economics $2^{\text {nd }}$ edition

Economists customarily talk about the 'realism' of economic models and of their assumptions and make descriptive and prescriptive judgements about them: this model has more realism in it than that, the realism of assumptions does not matter, and so on. This is not the way philosophers mostly use the term 'realism' thus there is a major terminological discontinuity between the two disciplines. The following remarks organise and critically elaborate some of the philosophical usages of the term and show some of the ways in which they relate to economists' concerns. In the philosophy of science, scientific realism is the mainstream position - or rather a heterogeneous collection of positions - that includes ideas about the nature of scientific theories and how they are related to the real world and about the goals and achievements of scientific inquiry. However, most of what philosophers have contributed around these ideas is not designed to deal with the peculiarities of economics, thus some important adjustments are needed to make scientific realism an interesting position for economists.

Economists and their critics, as well as the consumers of economic research, are often intrigued by two kinds of issue that connect with realism: Is this model about something real, something that really exists (or instead about some imaginary fiction or social construct perhaps)? Is this model true (partly true, approximately true) about something real (instead of just being useful or convenient or persuasive)? These are the general questions discussed here - not by answering them, but by way of clarifying the conceptual prerequisites of trying to answer them, and in particular by way of examining what it is to be a realist about them. Misuses of 'realism' are abundant enough to warrant this exercise. The focus will be on ontology, and on how realism relates to it - thus we will be mainly talking about ontological realism.

What exists?

Ontological realism is a philosophical thesis that deals with two questions: What exists? What is existence? Consider the first question. Slightly different ways of putting it include these:

What is there in the world?

What is the furniture of the world?

What is the world made of?

What is its structure?

What is the case?

What is the way the world is?

What is the way the world works? 
To such questions one expects answers of the form, ' $\mathrm{X}$ exists' or ' $\mathrm{Z}$ is the case' or 'WWW is the way the world works'. But isn't it the task of science to provide answers of this form to such questions? What is the role of distinct ontological reflection? The quick response is in two parts: the answers provided by ordinary scientific practice ('normal science') are often implicit and only presupposed, while ontological reflection seeks to make them explicit; and the explicit answers that daily scientific practice supplies are mostly more specific and concrete that those offered by focused ontological scrutiny. There is an overlap and continuity between 'normal' science and ontological reflection regarding the kinds of answers they seek to offer to those questions. Consistency between the two is desirable, even though occasional (and often fruitful) conflicts arise.

Scientists may claim that there are neural brain states and processes that cause human behaviour, or that there are beliefs and wants that causally produce such behaviour. Scientists may make claims about there being causal connections between certain aggregate variables, such as the money stock and inflation, or between inflation and unemployment. Such claims have ontological presuppositions, but practising scientists seldom engage themselves in explicating and elucidating them. Are there mental states such as beliefs and wants in addition to brain states? In referring to preferences and expectations in their explanations, are economists presupposing that they exist? Are there macroeconomic aggregates in addition to individuals and their attributes? Do economists commit themselves to their existence when invoking them in explaining economic phenomena? And what is causation all about? Is there just one kind of causation out there, or are there perhaps different kinds of causal connections and other causal facts, depending, among other things, on whether we talk about connections between brains, minds, individual action, or economic aggregates?

Explicitly or implicitly, economists hold presuppositional beliefs about such ontological matters. They give, or imply, answers to the sorts of questions above, provoked by developments and debates in economics, such as those around neuroeconomics and microfoundations. What does this have to do with realism? Not much, as such. Various alternative answers to those questions are compatible with ontological realism. One can be a realist about brains or minds, or both, and one can be a realist about human individuals or social institutions, or both. There is no single privileged "realism" that would determine the contents of our ontology - there is no such thing as "the realist ontology". It indicates a misunderstanding of 'realism' to suggest that there is one general "realist ontology" that has specific contents concerning issues such as law and causation, or the relations between human individuals and social structures. Realism as such does not imply specific answers to questions "What exists?" or "What is the case?" and the like.

Ontological realism is always Realism-about-X, thus we get a variety of realisms depending on the value of $\mathrm{X}$. So one can choose to be, or not to be, a realist about electrons, molecules, cells, minds, human individuals, and social organisations, as well as more generally about relations and causal processes, natures and necessities, numbers and sets, parts and wholes, material states and moral values. One can coherently be a realist about some such things while being an antirealist about others; one can be a realist about 
molecules without being a realist about morality, or vice versa. And, again, choosing to be a realist does not as such determine what you are a realist about. You choose Realismabout-X as a package, thus it is not your choice of realism that implies your choice of some specific X.

\section{What is existence?}

It also works the other way around. Your choice of $X$ as the kind of thing that you think exists does not yet make you a realist. In order to qualify as a realist it is not enough to hold that the hardware of the brain exists or that social structures are causally powerful, or what have you. The general form of the thesis of ontological realism is "X exists" or " $\mathrm{Z}$ is the case" or some such. It is not enough to be specific about the $\mathrm{X}$ and the $\mathrm{Z}$, one also needs to say more about the meanings of 'exists' and 'is the case'. No answer to "what exists" - no list of things that are claimed to exist or to be the case - is alone sufficient for ontological realism. We also need to carefully answer the question, "What is existence?"

\section{Irreducible existence}

Two requirements are needed in order to come up with an appropriate idea of existence. First, realism requires that existence claims be understood literally. Thus, one is a realist about $\mathrm{X}$ if one takes $\mathrm{X}$ to exist, and by this one means, literally, that $\mathrm{X}$ exists rather than ultimately meaning that something else exists. One is a realist about ions and institutions just in case one takes ions and institutions to exist, period. On the other hand, one is not a realist about $\mathrm{X}$ if one holds that $\mathrm{X}$ exists in the sense that $\mathrm{Y}$ exists in virtue of the fact that $\mathrm{X}$ is ultimately $\mathrm{Y}$. In such an antirealist manouvre one substitutes a reductionist reading for a literal reading of existence claims. This table at which I write exists in the sense that a certain bundle of atoms exists - tables are ultimately nothing but bundles of atoms. Or to say that the table exists is another way of saying that a certain collection of sense data exists - middle-sized material objects are collections of sense-data, literally speaking. Minds and mental states such as expectations exist, but their existence is a matter of human brains and neurons existing. A business corporation exists, but to say so is just a convenient way of speaking: it exists more precisely in the sense that an organised collective of human individuals exists - social collectives are sets of individual people after all. This way of using existence claims amounts to an ontologically reductionist strategy that allows for existence claims that are not supposed to be taken literally: an appropriately literal reading is a post-reduction reading. In contrast, an ontological realist about $\mathrm{X}$ reads 'X exists' literally and insists on its irreducibility to 'Y exists'.

Consider causation. In order to qualify as a realist about causation it is not sufficient to hold the view that there are causal facts in the world. It is also required that causation be viewed as an irreducible notion, one that cannot be analysed fully in terms of other, noncausal notions. For example, an ontological empiricist about causation might say that causation exists, and then add that it exists in the sense that empirical regularities or constant conjunctions of observable events exist - simply because this is what causation is, at the end. Here causation will be reduced to, or analysed into, non-causal facts. In 
philosophers' jargon, 'causal realism' is a name for a position that denies such a reduction and instead requires claims about causation to be taken at face value. For a realist, causation is, literally is, a matter of causing, producing, bringing about, propagating, enabling, inhibiting, and so on. A causal realist analyses causation in causal terms, whereas a causal antirealist analyses causation in non-causal terms and thereby analyses causation away.

So conceived, causal realism is an ontological position. This is compatible with epistemologies of causation that employ non-causal terms. David Hume seems to have been a causal realist - causation in the world is a matter of causes producing their effects - while at the same time his epistemological scepticism suggested that we only have epistemic access to constant conjunctions (see e.g. Strawson 1989). Or consider Grangercausality, defined partly in terms of predictability of effects. Predictability is an epistemic notion, thus a causal realist should not include it in his concept of causation in the world. But Granger-causality does not require such inclusion, thus as such it does not rule out the possibility of causal realism. The general idea behind it, that of providing an 'operational definition' of causation, does not require Humean scepticism either: Granger-causality can be thought of as a (fallible) element in the economists' imperfect epistemic endeavours to discover irreducibly causal relations in the world.

\section{Independent existence}

The second requirement for a position to qualify as realist is that it must hold that whatever exists has to exist in some suitable independent way. On this issue the peculiar features of society and the social sciences impose special requirements on the appropriate conception of realism. Ontological realism about some $\mathrm{X}$ - in its answer to the question, "what is existence?" - claims that X exists independently of some Z. Further versions of this idea depend on how 'independent' and ' $Z$ ' are specified.

The usual manner of defining ontological realism is in terms of mind-independence: some $\mathrm{X}$ exists independently of the human mind. But even though this idea would seem to apply to many sorts of things, it is problematic in the social sciences. While it may be plausible to claim that galaxies and quarks exist mind-independently, this does not seem a good idea in the case of, say, people's preferences and expectations or a society's institutions and organisations. The conventional existence test that tends to appeal to most people's intuitions, is to imagine a situation without minds: Take away human minds, will galaxies survive? Yes, they will. Take away human minds, will social institutions survive? No way. Social objects are mind-dependent. This does not require, of course, that whatever there is in society is intentionally created by people, as intended results of their purposeful action. Much of what there is in society is being produced as unintended consequences of the actions of people with minds.

Not only are social objects mind-dependent in general, they are also representationdependent. They are dependent on representations in general for the trivial reason that people are animals active in producing and using representations as an integral feature of human action. Moreover, and more strongly, many - but surely not all - social things are 
dependent on representations about them: the existence of $\mathrm{X}$ is dependent on representations of $\mathrm{X}$ - on being represented as X. Many contracts between economic actors only exist when linguistically represented. Take away the representation, and the contract ceases to exist. Likewise, Euro, the currency in use in most members of the European Union, is partly constituted by representations, among them certain Treaties of the European Council. In contrast, the existence of DNA molecules is not dependent on any particular representations of them: supposing they exist at all, they existed both before and after Watson and Crick's double helix representation, and independently of it.

Social reality is variously shaped by, and dependent on, people's beliefs and expectations, goals and wants, plans and impulses, emotions and reasonings, speech acts such as promises and persuasions, agreements and disagreements, collaborations and rivalries, meanings and their interpretations, customs and conventions, and so on. None of this is mind-independent in certain obvious senses.

Science-independence

Thus ontological realism about society and social sciences requires some other idea of independent existence. Here it is advisable to start being more precise about the issue: we are concerned with the ontology of scientific realism. This suggests that we need some notion of science-independence (an idea that has been largely ignored by philosophers debating scientific realism). A scientific realist takes galaxies and quarks to be independent of astronomy and physics, of the theories and explanations and procedures in these sciences. But consider social facts. Much of what there is in society is increasingly dependent on science, natural science included. This dependence works through various powerful influences of science on the worldviews and technologies prevalent in society. It is through these channels that people's beliefs and aspirations, and society's norms and institutions, are shaped by science. These constitute the stuff of which societies are made, thus social matters are not science-independent in an obvious sense.

What about the economy and the science of economics, how do they relate to one another? We can repeat some of the things we said above, and we can add an idea of a stronger dependence. The Lucas critique provides one expression to the old and obvious idea that the economy is not fully economics-independent. Many economic facts seem to be dependent on theories and procedures in the science of economics. Among the more striking cases, just think of the dependence of certain practices of finance in the real world on certain theories of finance - such as the Black-Scholes-Merton formula for option pricing (see MacKenzie 2006). Economic theories and research results shape people's beliefs and worldviews, and policy advice based on economic theories and research results shapes economic policies, and these in turn shape the economy. Economic theories, people's beliefs and economic facts are furthermore often connected through mechanisms of self-fulfilment and self-defeat. The economy is thus variously dependent on economics. One might suspect that the notion of science-independence does not serve scientific realism well in the case of economics.

In order to see why all this does not undermine scientific realism about economics and 
the economy, we need to pay attention to the notion of independence itself in 'exists independently of'. Of the many kinds of independence, it will be sufficient to distinguish two general categories (Mäki 2002).

Consider again the idea above about society being science-dependent just because science shapes the worldviews and technologies in society, and these in turn shape people's behaviour and social institutions. What kind of claim is this? I take shaping (or whatever similar terms one may want to use) to be a matter of causal influence. Thus, a causal claim is being made: social matters are causally dependent on science. This is a relief to a realist about society and social sciences since such causal dependence can easily be accommodated by scientific realism.

Scientific realism does not need to deny or despair over the causal dependence of the economy on economics either. The causal influences of economics on the economy travel through obvious channels. Policy makers and others (such as students, investors, entrepreneurs, workers, consumers) learn, directly or indirectly, about economic theories, explanations and predictions, and are inspired by them enough to modify their beliefs. These modified beliefs make a difference for the behaviour of these actors, and this has consequences for the economy. The connections, and hence the dependencies, are causal.

The same holds for cases in which the connections from theory to the world change the latter so as to make the theory more closely correspond to the world - often characterized as the "performativity" of theory. If it is the case that students of economics act more than other students in accordance with the conventional behavioural assumptions of economic theory, this might be because their image of appropriate human behaviour and thereby heir actual behaviour is influenced by what they are taught in class. If certain practices in real world finance are in line with the Black-Scholes-Merton formula for option pricing, this may be because the theoretical formula has managed to travel from academic research to economic practice so as to shape the latter. In such cases, the connections are causal.

Rather than constituting a threat to realism, such causal connections between economic theory and the economy pose a constructive challenge to realism. The economy is organised into causal structures and processes, and investigated by economists. Adding economic theory to the picture in some cases means adding another causal set of connections to our image of social reality - science is not done outside of society, it is very much part of social reality, after all. This invites further scientific inquiry into the detailed features of these causal connections. Good social science illuminates the roles that ideas play in the social world. Good social science should also illuminate the roles that scientific ideas play in the social world.

A realist is comfortable with causal connections in general, thus is not disturbed by causal connections from theories to the world either. To see why, it is important to be precise about the nature of this dependence. Indeed, literally speaking, there is no causation flowing from theories to the world here. Economic theories do not shape the economy. People do. People, in various roles as economic actors, are inspired, directly or 
indirectly, by the contents of economic theories, this shapes their beliefs, their beliefs shape their motives, and those motives drive them in action that shapes the economy. Phrases such as 'self-fulfilling' and 'self-defeating' theories and predictions are therefore not to be taken literally: theories do not fulfil or defeat themselves (Mäki 2002, 2005a). If they had the capacity to do so, scientific realism would be defeated. Likewise, the idea of 'performativity' of economic theories is not to be understood literally: theories or their utterances alone do not serve performative functions in the sense of themselves giving rise to what those theories are about.

\section{Social construction}

So scientific realism is comfortable with a lot of science-dependence of society. What sort of science-dependence does scientific realism rule out? As an analogy, consider any of the numerous economist jokes (such as "No Reality, Please. We're Economists." Blaug $2002,36)$. There is no way the joke could be funny without being perceived as such. The joke's being funny is constituted by some people - not necessarily economists - finding it funny. Being funny and being perceived as funny are inseparable, not because the funnyness of the joke (causally) makes people laugh, but because their laughter (conceptually) makes it funny. The connection is not causal - as in funny jokes causing people to find them funny - but rather conceptual or constitutive - being perceived as funny is part of the definition of 'funny', or partly constitutes what it is to be funny.

Economic facts in social reality would have the same status as funny jokes if they were facts only if perceived to be so by economists. The economy being in state $S$ and some of its developments being governed by mechanism $\mathrm{M}$ are so just because economists hold theories and other beliefs that say so. This is what the realist will deny. A realist will grant there is a formal contract between two economic actors only provided these actors believe it is there, and they - perhaps together with third parties - have agreed to represent the contract. But a scientific realist about the economics of contracts takes those contracts to be science-independent in the sense of not being created by acts of economic theorising. The contracts exist and have the properties they have independently of being believed or claimed to be so by economists. While facts about contracts are constituted by the beliefs and representations by contracting parties, they are not constituted by acts of scientific theorising about them. Creating a theory of $\mathrm{X}$ is not a matter of creating $\mathrm{X}$. Creating a theory of (the causation of) business cycles does not, just by that token, create (that very causation of) business cycles. Saying so does not make it so.

This idea of non-causal science-independence suggests how to identify some of the opponents of scientific realism. They are those who do not subscribe to the non-causal science-independence of matters of fact in the world, including social and economic facts. Of contemporary (both academic and broader cultural) relevance are forms of social constructivism (see Hacking 1999). This is a doctrine that comes in an obscure variety of forms that are characteristically not distinguished from one another. Modest versions claim that beliefs about the world are outcomes of social construction (including education, negotiation, persuasion, testimony, imitation, indoctrination, herd behaviour, group pressure, cognitive path dependency, and other social processes). More radical 
versions claim that the world itself is socially constructed. More weakly, one may argue that beliefs and myths about gender, race, and schizophrenia are socially constructed - or that scientific theories about atomic structure and evolution are so constructed. More strongly, one may argue that that gender and race, as well as quarks and evolution, are products of social processes.

Realism is comfortable with weaker forms of social constructivism. Generally held beliefs about the world are socially constructed - simply because cognition is essentially social activity, with numerous cognitive agents interacting with one another under changing institutional constraints, Moreover, parts of the world itself are socially constructed in obvious ways. Indeed, society itself is socially constructed: social objects, properties, states, and processes are outcomes of social processes. Since this is a general fact about social reality, ontological realism about society grants it.

So what does realism rule out when it comes to society and social sciences? It is incompatible with positions that deny the non-causal science-independence of social matters. Claiming that social facts are socially constructed by social scientists just by way of constructing concepts and theories about society is beyond the scientific realist. A special version of this is the idea that social facts - certain ordinary kinds of facts about society outside of the academia - emerge as an outcome of rhetorical persuasion by economists of their audiences: certain facts about, say, the causation of inflation emerge as soon as masses of economists and others are persuaded by monetarist economists about the causal link between money and inflation. What precisely is the problem with this thought that bothers a realist? First consider what realism accepts. What the realist will accept is that the beliefs held by economists about the causation of inflation are socially constructed by ordinary social processes of academic (and possibly nonacademic) persuasion. The realist also accepts that the beliefs held by people other than academic economists - such as politicians, journalists, union leaders, and consumers - are outcomes of persuasion. Finally, realism accepts that such beliefs may motivate behaviour that has consequences for the causal connection between money and inflation. Such a connection between beliefs and behaviour is part of the causal structure giving rise to actual inflation rates. So what does realism deny? It denies the radical social constructivist idea that when an economist puts forth a theory about the causation of inflation and manages to get it generally accepted, this alone will give rise to the causal facts described by the theory. This is to deny that agreement without action is sufficient for making or changing the world.

For a realist, theory construction does not amount to world construction. Even theory dissemination alone is not sufficient for world construction (where 'world' refers to what the theory is about). Of course, it is a social fact that masses of people are persuaded about whatever, and this indeed is an outcome of rhetorical practices. What a realist should deny is that what those people are persuaded about, is itself constructed just by those rhetorical practices. Again, it is a different idea that people so persuaded may take action and this action may make a difference for some social facts. This requires that the beliefs adopted in consequence of persuasion become causally efficacious in relation to actual behaviour. But this gives us what I called causal construction, and it is compatible 
with scientific realism.

\section{Model worlds}

Much of social constructivism may be inspired by the observation that scientists do not have direct access to the details and complexities of the real world. Scientists do not directly investigate the messy concreteness and complexity of the world, but rather engage in various manoeuvres that seek to "prepare" that world for closer inspection. Economists will easily recognise this as part of their model building practises. Faced with the immense complexity of the world, economists are forced to simplify their images of it by way of using various procedures of omission, idealization, and abstraction. The models they build and employ isolate small slices of the world for detailed scrutiny while leaving most details out of the picture. Such procedures of isolation are among those manoeuvres of preparation, and they result in models that appear to describe simple imaginary model worlds rather than the real world.

One may then say that models and model worlds are constructed rather than, say, discovered, and that they are socially constructed just because scientific work is intrinsically a social activity. The realist grants this much, but then goes on to insist that even if economic models of the social world are socially constructed by economists, the social world itself is not socially constructed by the modelling practices of economists.

At this point it will be helpful to have an account of models that is able to deal with this set of issues (Mäki 2005b). I take models to be what can be called substitute systems or surrogate systems that serve as direct subjects of inquiry. They are substitute systems in that they are examined instead of the real systems that they replace and stand for. The real systems "out there" may be too complex (such as social systems), too far away in time or space (such as the origin of the species) to be capable of being directly investigated, or it might be unethical to examine the real system directly (such as using human subjects for medical experimentation). Much of scientists' activity is a matter of building and manipulating such substitute systems in order to learn about their properties and behaviour. A realist about models and the real world would add that the properties of models are directly examined by scientists in order to indirectly learn about the properties of the real world.

A radical social constructivist will not buy this image. In a radical constructivist framework, there is no distinction between model systems and real systems, nor is there room for an idea of indirect acquisition of information about the latter by way of examining the former. There are only socially constructed model systems, and it is a matter of power and persuasion which models will be taken to provide the facts. This is one way of illuminating the strong social constructivist ontology in a nutshell.

Truth

This takes us to the issue of truth. Economists appear to have great difficulties with applying the concept of truth. They characteristically believe that since models do not 
reproduce the whole complexity of their subject matter, they are necessarily false, or that because models involve false assumptions, models themselves are false. In order to see why these beliefs about the falsehood of models are false, we should take a realist perspective to the ontology of truth. This will help further clarify the very concept of realism. Here the focus is on what truth is (rather than what is true). (See Mäki 2004)

Truth is a property of truth bearers. A truth bearer is true just in case there is a truth maker that makes the truth bearer true. The sentence, or statement, 'The cat is on a mat' is a truth bearer that is made true by its truth maker in the world, namely the cat being on a mat. 'Education is a major cause of economic growth' is a truth bearer that is made true by its truth maker, namely education being causally responsible for at least $15 \%$ of the growth in the output of an economy (supposing this is how we have defined 'major'). Now all models of the connection between education and growth omit lots of things in the world and make false idealizing assumptions about others. But whether one takes a model to convey true information about the world depends on what one takes the relevant truth bearers to be. In the case that the intended truth bearer is, say, 'Education is responsible for about one quarter of economic growth (in some spatio-temporally specified location)", then its truth makers include those situations in the real world in which education is causally responsible for 23-27\% of growth (supposing this interval is what we meant by 'about one quarter'). In the case that the intended truth bearer is something different, namely a description of the causal mechanism by way of which education contributes to growth, then its truth maker would be that mechanism in the real world (such as some skill mechanism or a signalling mechanism, depending on what we seek to describe with the model).

No model offers the whole truth of its domain, and no model, if spelled out in full, is devoid of false elements (false if considered as potential truth bearers). Understanding that models can be true, or can be used for making true claims, requires understanding the intended relevant truth bearers. These intuitions provide the basis for resisting the popular idea that models cannot possibly be true.

The realist ontology of truth so conceived is rather straightforward. Realism requires that the relevant truth makers be real, that they exist in a suitably independent manner. Truth makers are, after all, just those things the existence of which ontological realism deals with. Truth makers must exist without being non-causally science-dependent. Creating a model of a signalling mechanism does not create that signalling mechanism: the mechanism exists (if it does) independently of any economic models about it - it exists even though there were no models about it.

What does realism say about truth making, the way in which truth makers make truth bearers true? Again, a suitable independence requirement is imposed. The way in which truth makers make true statements or models true must be independent of our ways of coming to hold beliefs about their truth. In particular, epistemic matters do not enter truth by way of, say, making truth making dependent on evidential considerations or our capacity to recognise truth. So, we do not make true models true by coming to recognise them as true in virtue of having collected lots of supportive evidence, or having become 
persuaded by the most prestigious economists, or the like. While we make truth bearers, we do not make them true. Facts do.

Possible existence and possible truth

Here is an important further qualification of what it takes to be a realist about the world and models about it. Above, I have said that it is not sufficient to hold that some entity X exists and that theory $\mathrm{T}$ is true about $\mathrm{X}$ in order to count as a realist about $\mathrm{X}$ and $\mathrm{T}$ (it is not enough because one has to add further restrictions in terms of irreducibility, noncausal science-independence, and independence of epistemic attitudes, for example). It is now time to weaken this by saying that holding those ideas is not necessary either. It is enough for a realist to hold the view that $\mathrm{X}$ might exist and $\mathrm{T}$ might be true about $\mathrm{X}$, that it is possible for $\mathrm{X}$ to be the case and $\mathrm{T}$ to be true. Such a view will reveal a realist attitude: there is a fact of the matter concerning whether or not $\mathrm{X}$ exists and whether or not $\mathrm{T}$ is true. It is an attitude that will give real existence and objective truth a chance, but one that at the same time is prepared for concluding that $\mathrm{X}$ does not exist or $\mathrm{T}$ is not true, after all. This is an advisable attitude for epistemically insecure and self-critical scientific practice based on consistent fallibilism.

Ontological realism about $\mathrm{X}$ is primarily an account of what it is for $\mathrm{X}$ to exist (if it does). To this, one may add the weaker claim that $\mathrm{X}$ might exist, or the stronger claim that $\mathrm{X}$ does exist. Likewise with truth. Realism about truth is primarily an account of what it is for a truth bearer $T$ to be true. One may then add the weaker claim that $\mathrm{T}$ might be true, or the stronger claim that $\mathrm{T}$ indeed is true. Naturally each such claim requires different sorts of supportive argument.

The bite of ontology

Does ontology make a difference for scientific practice and its evaluation? That ontology may have some bite is evident even in the case of the weak version of realism put in terms of possible existence. Some economists criticise the model of perfect competition on the grounds that perfect competition is not even conceivable: its perfection has been taken so far that such a competitive market has become an impossibility (Richardson 1960). If this is correct, then ontological realism would be an inappropriate attitude regarding perfect competition as depicted by the model.

In general, economists hold, or entertain, ontological convictions, explicitly or implicitly, and these may have consequences regarding the preferred ways of theorising and explaining. Whatever mismatch there may be between ontology and economic theory, sometimes it plays an important role in driving intellectual progress, sometimes not. When there is a clash between the ontological convictions of an economist and the apparent ontological implications of a theory held by this economist, there may be a healthy pressure to revise the theory so as to realign ontology and theory. Such a clash may, in suitable circumstances, serve as a driving tension that creates pressure to modify theories or invent new theories such that the economist will be able to take the theory with an ontologically realist attitude. An economist may, deep down in his convictions, 
view certain facts - such as increasing returns, bounded rationality, and institutional structure - as causally powerful features of the economy. At the same time, the modelling conventions and techniques of the discipline may be such that the economist will be unable to incorporate such things in his models. There is a tension that needs to be resolved, and the resolution will be sought in the spirit of ontological realism.

Yet, in general, one's favourite ontology does not determine the contents of theory or model used, nor is it determined by these. The impact of ontology is rather a matter of constraint. In many cases even this much impact is too much. An economist may correctly say things that are quite appropriate in their respective contexts even though those things may clash with deeper ontological convictions, An economist may appropriately say "this country is applying monetarist tenets in its economic policies" even though the deeper conviction may be in line with ontological individualism claiming that no such collective entities as countries exist - only individuals do. Or an economist may say that "individuals have preferences" while a philosopher of mind or a neuroeconomist may endorse the ontological claim to the effect that "preferences do not exist" simply because she believes nothing mental does: preferences really are just configurations of neural states. To claim that individuals have preferences as part of economic discourse does not contradict the eliminativist materialism endorsed by the philosopher - just as the claim "there are fifteen chairs in the seminar room" may be correct even though one's philosophical ontology may imply that chairs do not exist, while bundles of atoms do. In such cases, there is no conflict between the two claims in each pair due to the idea that one of the claims, and only one of the claims, informs us, after all, how things are "at bottom" or "ultimately".

A parallel idea is that ontology does not determine methodology, but rather serves as a constraint on it. Thus ontological individualism (the belief that only individuals exist) does not imply a commitment to methodological individualism - the obligation to spell out the microfoundations of economic theories and explanations. The economist may legitimately decide that the things he or she wishes to know can be established using aggregative models not grounded in individual behaviour. For example, it may be that certain facts depend on distributions across individuals and not on individuals themselves. Similarly, the conventional procedure of theoretical isolation (isolating certain phenomena that are to be analysed) by building models of small and simple hypothetical worlds does not imply the ontological conviction that the actual systems in the real world are equally simple and isolated from other aspects of reality. What economists do believe is that in order to study complex systems, simple models are needed, because the real world is too complicated and because the limited questions asked about it require focusing attention on a limited set of mechanisms (while ontological realism may be used to require that these mechanisms exist also in the complex real world).

Methodology is under-determined by ontology. It depends on ontology but it also depends on other things such as the cognitive interests of the inquirers and their limited cognitive capacities. But even this much is enough for concluding that ontology matters. 


\section{References}

Blaug, Mark (2002) "Ugly current in modern economics", in Fact and Fiction in Economics. Realism, Models, and Social Construction, ed. U. Mäki. Cambridge: Cambridge University Press. Pp. 35-56.

Hacking, Ian (1999) The Social Construction of What? Cambridge MA: Harvard University Press.

MacKenzie, Donald (2006) An Engine, Not a Camera. How Financial Models Shape Markets. Cambridge, MA: MIT Press.

Mäki, Uskali (2002) "Some non-reasons for non-realism about economics", in Fact and Fiction in Economics. Realism, Models, and Social Construction, ed. U. Mäki.

Cambridge: Cambridge University Press. Pp. 90-104.

--- (2004) "Some truths about truth for economists, their critics and clients", in Economic Policy-Making under Uncertainty: The Role of Truth and Accountability in Policy Advice, ed. P. Mooslechner, H. Schuberth, and M. Schurtz. Cheltenham: Edward Elgar. Pp. 9-39.

--- (2005a) "Reglobalising realism by going local, or (how) should our formulations of scientific realism be informed about the sciences" Erkenntnis, 63 (2005), 231-251

--- (2005b) "Models are experiments, experiments are models", Journal of Economic Methodology, 12 (2005), 303-315.

Richardson, George (1960) Information and Investment. Oxford: Clarendon.

Strawson, Galen (1989) The Secret Connexion. Causation, Realism, and David Hume. Oxford: Clarendon. 